Subscriber access provided by Caltech Library

Ecotoxicology and Public Health

\title{
Ambient PM Toxicity is Correlated with Expression Levels of Specific MicroRNAs
}

Haoxuan Chen, Xiangyu Zhang, Ting Zhang, Xinyue Li, Jing Li, Yang Yue, Minfei Wang, Yunhao Zheng, Hanqing Fan, Jing Wang, and Maosheng Yao

Environ. Sci. Technol., Just Accepted Manuscript • DOI: 10.1021/acs.est.0c03876 • Publication Date (Web): 13 Jul 2020

Downloaded from pubs.acs.org on July 14, 2020

\section{Just Accepted}

"Just Accepted" manuscripts have been peer-reviewed and accepted for publication. They are posted online prior to technical editing, formatting for publication and author proofing. The American Chemical Society provides "Just Accepted" as a service to the research community to expedite the dissemination of scientific material as soon as possible after acceptance. "Just Accepted" manuscripts appear in full in PDF format accompanied by an HTML abstract. "Just Accepted" manuscripts have been fully peer reviewed, but should not be considered the official version of record. They are citable by the Digital Object Identifier (DOI®). "Just Accepted" is an optional service offered to authors. Therefore, the "Just Accepted" Web site may not include all articles that will be published in the journal. After a manuscript is technically edited and formatted, it will be removed from the "Just Accepted" Web site and published as an ASAP article. Note that technical editing may introduce minor changes to the manuscript text and/or graphics which could affect content, and all legal disclaimers and ethical guidelines that apply to the journal pertain. ACS cannot be held responsible for errors or consequences arising from the use of information contained in these "Just Accepted" manuscripts. 

9

\title{
Ambient PM Toxicity is Correlated with Expression Levels
} of Specific MicroRNAs

$$
\text { Haoxuan Chen }{ }^{1} \text {, Xiangyu Zhang }{ }^{1} \text {, Ting Zhang }{ }^{1} \text {, Xinyue Li }{ }^{1} \text {, Jing Li }{ }^{2} \text {, Yang Yue }{ }^{3,4} \text {, }
$$$$
\text { Minfei Wang }{ }^{1} \text {, Yunhao Zheng }{ }^{5} \text {, Hanqing Fann }{ }^{6} \text {, Jing Wang }{ }^{3,4} \text {, Maosheng Yao }{ }^{1, ~ *}
$$

$$
\begin{aligned}
& { }^{1} \text { State Key Joint Laboratory of Environmental Simulation and Pollution Control, } \\
& \text { College of Environmental Sciences and Engineering, Peking University, Beijing } \\
& \text { 100871, China }
\end{aligned}
$$

${ }^{2}$ Linde + Robinson Laboratories, California Institute of Technology, Pasadena, CA, 91125, United States

${ }^{3}$ Institute of Environmental Engineering, ETH Zurich, Zurich 8093, Switzerland ${ }^{4}$ Laboratory for Advanced Analytical Technologies, Empa, Swiss Federal Laboratories for Materials Science and Technology, Dubendorf 8600, Switzerland ${ }^{5}$ Institute of Environment and Sustainable Development in Agriculture, Chinese Academy of Agricultural Sciences, Beijing 100081, China

${ }^{6}$ Department of Earth and Environmental Engineering, Columbia University, New York, New York 10027, United States

\section{Revision Submitted to}

Environmental Science \& Technology

\author{
* Corresponding Author: \\ Maosheng Yao, PhD \\ Boya Distinguished Professor \\ E-mail: yao@pku.edu.cn, Tel: +86 01062767282 \\ Beijing, CHINA \\ July 11,2020
}




\section{Abstract}

Uncertainties for optimized air pollution control remain as the underlying mechanisms of city-specific ambient particulate matter (PM)-induced health effects are unknown. Here, water-soluble extracts of PMs collected from four global cities via automobile air conditioning filters were consecutively injected three times by an amount of 1, 2 and $2 \mathrm{mg}$ into the blood circulation of Wistar rats after filtration by a $0.45 \mu \mathrm{m}$ pore size membrane. Acute health effects such as immune and inflammatory responses and hemorrhage in alveoli were observed right after the PM extraction injection. Significant differences between cities in biomarker TNF- $\alpha$ and MCP-1 levels were detected following the second and third PM injections. Rats' inflammation responses varied substantially with the injections of city-specific PMs. Repeated PM extract exposure rendered the rats more vulnerable to subsequent challenges; and down-regulations of certain microRNAs were observed in rats. Among the studied miRNAs, miR-125b and miR-21 were most sensitive to the PM exposure, exhibiting a negative dose-response type relationship with source-specific PM (oxidative potential) toxicity $\left(r^{2}=0.63\right.$ and $0.57 ; p$-values $\left.<0.05\right)$. The results indicated that city-specific PMs could induce different health effects by selectively regulating different miRNAs; and certain microRNAs, e.g., miR-125b and miR-21, may be externally mediated to neutralize PM-related health damages.

Keywords: Particulate Matter; Toxicity; MicroRNA; Inflammation; Biomarker; Catheter-embedded Rat Model 
51

52

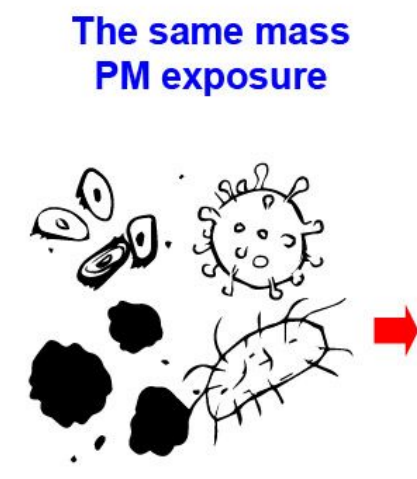

Particulate Matter

53

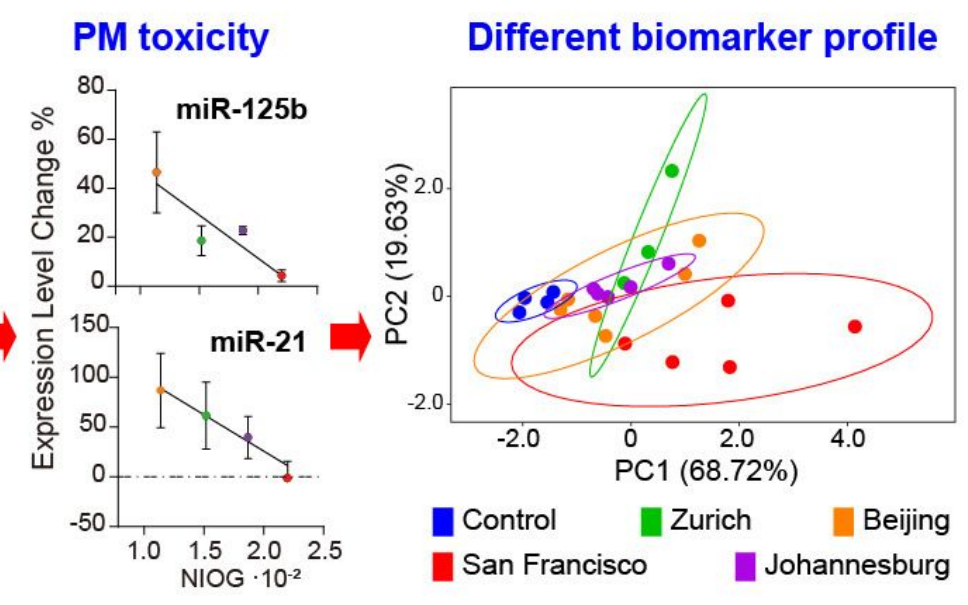

54 


\section{Introduction}

Air pollution, especially the particulate matter, has become a growing global health concern. Exposure to particulate matter with a diameter of no more than 2.5 micrometer $\left(\mathrm{PM}_{2.5}\right)$ is estimated to have resulted in 4.2 million deaths in 2015 worldwide. ${ }^{1-2}$ Particularly for Asian countries, there were more severe haze episodes in recent years with much higher average levels of ambient $\mathrm{PM}_{2.5}$, which accordingly explains for more air pollution related deaths from these regions. ${ }^{1-2}$ For example, China and India together had the largest numbers of attributable deaths to the total 4.2 billion deaths: 1.11 and 1.09 million, respectively; while the United States alone had 0.09 million. ${ }^{1}$ Yet, it is interesting to note that the actual investigated mortality rates of these different regions resulting from air pollution tell a different story. For instance, according to an epidemiologic study conducted in 272 Chinese cities, the magnitude of the associations between short-term exposure to $\mathrm{PM}_{2.5}$ and increased mortality from various cardiopulmonary diseases in China was lower than those reported in Europe and North America. ${ }^{3}$ In addition to its mass level and many others, the observed difference could be also resulting from the different compositions of different sourced PMs, which result in different PM toxicity as previously found for global cities. ${ }^{4}$

To investigate PM toxicity, biomarkers in cultured cells (in vitro test) or animal and human samples such as bronchoalveolar lavage fluid (BALF), blood and urine (in vivo test) are widely used in both epidemiological and toxicological studies. ${ }^{5}$ IL-6 and TNF$\alpha$ have been chosen as biomarkers along with other cytokines or chemokines to indicate immune and inflammatory responses. ${ }^{6-7}$ To some extent, biomarker level changes can signal an inflammatory response to the toxicity of PM. In our previous work, breath-borne IL-6 was online monitored to reflect the inflammatory levels in rats after being injected with extractions of PMs collected from different cities. ${ }^{8}$ In addition to these protein markers, microRNA has been increasingly used in studying environmental exposure and health effects. ${ }^{9}$ MicroRNAs (miRNAs) are a series of post- 
transcriptional regulators of gene expressions. It is believed that microRNAs play important roles in many developmental and cellular processes. ${ }^{10}$ In general, microRNA guides RNA-induced silencing complex (RISC) to target mRNA in the $3^{\prime}$ untranslated region (UTR), then represses or degrades its translation. Accordingly, most microRNAs are expected to reduce the mRNA levels and protein expression of the target genes. ${ }^{11}$ Several microRNAs such as miR-125b, miR-155, miR-146a, and miR-21 were found to be closely involved in the innate immune and inflammatory process and widely investigated in air pollution related studies. ${ }^{9,} 12$ For example, in an cohort study of steel plant workers, it was reported that miR-21 responded to the production of reactive oxygen species (ROS) in the blood due to the PM-induced increase in oxidative stress. ${ }^{13}$ Besides, it was shown that exposure to ambient particles could cause downregulations of related microRNAs, such as miR-126, miR-146a, miR-155, miR-21, etc. ${ }^{14}$ However, how their regulations vary with different toxicity PMs from different sources is not clear.

Here, this work was carried out to mainly investigate: 1) Whether there are inflammation biomarker differences in repeated exposures of PMs from different cities on an animal's protein biomarker level? 2) What specific miRNAs are expressed when rats are exposed to PMs of different sources? 3) If there is a toxicity dependence for the expressions of specific miRNAs? Different from DTT (Dithiothreitol) assay for PM toxicity analysis, we employed an animal-based $\mathrm{PM}_{2.5}$-toxicity protocol developed in our lab which uses the intravenous injection to expose rats to PMs. ${ }^{15} \mathrm{PM}$ samples collected from world cities via automobile filter method ${ }^{4,16}$ were used in this work. PM water-soluble extracts filtered using $0.45 \mu \mathrm{m}$ syringe filters were directly injected into the blood circulation of rats in this study. Serum biomarkers (TNF- $\alpha$, MCP-1 and IL-1 $\alpha$ ) and blood plasma microRNAs (miR-146a, -125b, -126, -132, -155, -21, -223 and -26a) were measured in the exposure experiments. Histopathological analysis of organs (heart, liver, spleen, lung, kidney) were also performed. Differences in PM toxicity and also the molecular responses induced were analyzed. Results from this 
work provide information about dose-response relationship between PMs with different toxicity and biomarker expression as well as miRNA regulations, and further shed new light on the underlying health effect mechanisms of source-specific PM exposure.

\section{Materials and Methods}

PM Sampling and Preparation

The PM samples from Beijing, San Francisco, Zurich, and Johannesburg were collected using automobile air conditioning filters, and then the pooled PM ( $\mathrm{N}=5-15$ auto filter samples from each city) water-soluble components were extracted by normal saline. The sampling and extracting protocols were described in our previous studies. ${ }^{4}, 16$ Extracts of pooled PM samples from each city were prepared in two suspensions using normal saline: $1 \mathrm{mg} / \mathrm{mL}$ and $2 \mathrm{mg} / \mathrm{mL}$, and filtered by a $0.45 \mu \mathrm{m}$ pore sterile PTFE hydrophilic Syringe filter (Agela Technologies Inc., China) before the injection.

\section{Rat Breeding and PM Injection}

Male Wistar rats $(n=30)$ at an age of 10 weeks weighing $200-250 \mathrm{~g}$ were purchased from Beijing Vital River Laboratory Animal Technology Co., Ltd. All rats were performed an operation embedding a flexible sterile catheter into the jugular vein with $1 \mathrm{~cm}$ of catheter out of the skin and fixed onto the back of the rat with staples. Extracts injection and blood sampling were performed through the catheters using sterile syringes with $23 \mathrm{G}$ flat-end needles. Detailed catheter operation protocol as well as the injection and blood sampling were described in our previous work. ${ }^{15}$ All rats were kept inside a house-made cabinet with 24-h ventilation, 24-h video recording, 12:12 light-dark cycle, food and water ad libitum. After one week of acclimation, the rats were randomly divided into five groups right before the experiments: Control group, San Francisco group, Zurich group, Johannesburg group and Beijing Group (each group consisted 6 rats). PM water-soluble extracts of different cities after the 
143 filtration were injected into the blood circulation of rats from corresponding groups.

144

As shown in Figure S1 (Supporting Information), in order to investigate the health effects induced by repeated exposures of PMs, we performed three separate injections of PM extracts at different times. The first injection was on day 0 (the first day) with $1 \mathrm{~mL}$ of $1 \mathrm{mg} / \mathrm{mL}$ extracts for each rat, and the following two injections were carried out on day 3 (three days later) and day 7 (seven days later) respectively with 1 $\mathrm{mL}$ of $2 \mathrm{mg} / \mathrm{mL}$ extracts each time. The control group rats were injected with normal saline with the same volume. Here, use of $1 \mathrm{mg}$ or $2 \mathrm{mg}$ PMs was based on approximate 1-year inhalation exposure of rats to ambient average PM levels of 50 $\mu \mathrm{g} / \mathrm{m}^{3}$ or $100 \mu \mathrm{g} / \mathrm{m}^{3}$, respectively, assuming a body weight ratio of 300 (human vs. rat) and a human breathing rate of $12 \mathrm{~L} / \mathrm{min}$. Although the injection does not reflect a true exposure, it represents the worst scenario where all inhaled particles could possibly get into the blood especially after the filtration. After the injection, both control and exposed groups were physically monitored using video camera. On day 14 , twenty rats (four rats from each group, randomly selected) were euthanized by using pentobarbital sodium (Beijing Skillsmodel Biotechnology Co., Ltd) and anatomized for the histopathological analysis. The remaining rats from each group were kept for the follow-up observation of chronic health effects as additional evidence until day 473 (one year and 108 days), during which the weight of rats was recorded every 7-10 days. Because of lab space limitation and resource constraint, not all rats could be kept for long-term observation. All animal experiments were approved by the Institutional Review Board of Peking University, and the experiments were performed in accordance with ethical standards (approval \# LA2017204).

\section{Blood Sampling and Measurement}

Blood samples were taken $(0.3 \mathrm{~mL}$ for each time) before the injection and $1 \mathrm{~h}$ later after the injection. After a 20-min standing at room temperature, blood samples were subjected to centrifugation (5804 R, Eppendorf Inc., Germany) at $3000 \mathrm{rpm}$ for $10 \mathrm{~min}$ 
172 to separate serum from plasma. The supernatant serum and plasma were stored 173 separately at $-20^{\circ} \mathrm{C}$ for further analysis. Serum biomarkers including monocyte 174 chemoattractant protein-1 (MCP-1), tumor necrosis factor- $\alpha$ (TNF- $\alpha$ ) and interleukin$1751 \alpha($ IL-1 $\alpha)$ were measured using a Rat Cytokine/Chemokine Magnetic Bead Panel 176 (Merck Milliplex, Cat. \#RECYTMAG-65K, RECYMAG65K27PMX, RECYMAG65PMX27BK), 177 according to the manufacturer's instructions. As shown in a previous study, exposure 178 to ambient particles could cause down-regulations of related microRNAs. ${ }^{14}$ Thus, the 179 blood plasma microRNAs including miR-146a, miR-125b, miR-126, miR-132, miR-155, miR-21, miR-223 and miR-26a were measured using a qRT-PCR array. The experiments were conducted at Wcgene Biotech, Inc., China. RNA isolation, primers and cycling condition of miRNA qRT-PCR were described in the Supporting Information (Table S1).

\section{Anatomy and Histopathological Analysis of Rats' Organs}

After the rats were sacrificed, heart, liver, spleen, lung and kidney from the rats were taken and subsequently washed using normal saline. Then, the organs were steeped in $4 \%$ formaldehyde solution provided by Wuhan Servicebio Technology for 72 hours. The fixed organs were subjected to dehydration and paraffin-embedded as the preparation of tissue section. Then the cross sections were mounted onto the glass slides and deparaffinized. All the slides were stained with hematoxylin and eosin (H\&E) for histopathological analysis. At least 20 slides were obtained and examined from the samples taken from each organ of each rat. Experiments including dehydration, embedment, cutting, deparaffinization and HE stain were conducted by Wuhan Service Biotechnology Corporation.

\section{Statistical Analysis}

The statistical differences in serum MCP-1, TNF- $\alpha$ and IL-1 $\alpha$ concentrations among different groups were analyzed via one-way ANOVA (data exhibited a normal distribution) or Kruskal-Wallis one-way ANOVA on Ranks (data did not follow a normal distribution or equal variance test failed). To determine the expressions of microRNAs, 
201 a relative fold value was calculated using the $2^{-} \Delta \mathrm{Ct}$ method. ${ }^{17-18}$ Differences in microRNAs expression among different groups were also analyzed via one-way 203 ANOVA. All statistical tests were performed with Graph Pad 8.0 prism software. Besides, the software R (x64 3.6.2) with package "ggord" was used to visualize the biomarker profile distance and relatedness of different groups using the principal component analysis (PCA). The software R (x64 3.6.2) with package "vegan" was used to study the relationship between the biomarker profiles, PM toxicity and the microRNAs expression levels among different groups using the Redundancy analysis (RDA). In this study, due to the sampling or testing failure, the effective sample size of each group was shown in Table S2 (Supporting Information). For all the biomarkers and miRNAs studied, we had at least three values from each group. A p-value of less than 0.05 indicated a statistically significant difference at a confidence level of $95 \%$.

\section{Results and Discussion}

Toxic effects of PM injection to Rats Revealed by Protein Biomarkers and Pathological Observations

217 The concentration percentage changes of TNF- $\alpha$, MCP-1 and IL-1 $\alpha$ in blood sera of rats 218 from different groups on three consecutive independent injections are shown in 219 Figure 1(A). The concentration percentage changes of biomarkers for each injection were calculated by dividing the biomarker concentration $1 \mathrm{~h}$ after injection by the

221 concentration before the injection. As shown in the figure, levels of three biomarkers 222 increased after each injection, which indicated an acute inflammatory response 223 induced by PM water-soluble extracts within one hour after the injection. The 224 surveillance video (Figure 1(B) and Supporting Information Video S1) also showed that rats appeared to be drowsy after injected with PM extracts, i.e., staying in the corner 226 of the cage without moving around much after the PM injection; while the rats in the

227 NS (control) and Beijing groups moved around the cage and were relatively sensitive 228 to external interruptions. In a recent study, similar behavioral discrepancies were 229 observed between groups of rats injected with high and low doses of $\mathrm{PM}^{15}$, suggesting 
that the PM injected into the blood circulation indeed caused acute health effects to

231 rats. In future efforts, rat behavior/movement analysis software can be used to

232 quantitatively assess the behavioral differences between different rats. Previously, it

233 was clearly shown using Beijing PM samples that adverse health effects depend on the

234 PM mass injected. ${ }^{15}$ Using world cities' PM samples, we further demonstrated here

235 that PM toxicity in addition to mass also played a very important role for PM-related

236 health effect.

237

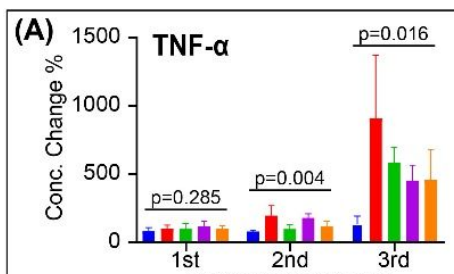

PM Extracts Injection

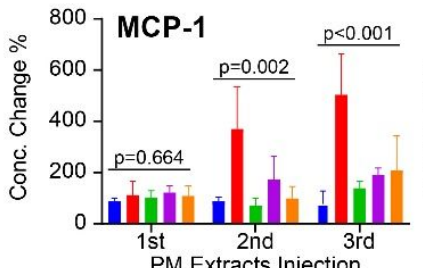

PM Extracts Injection

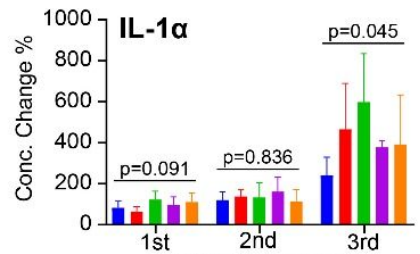

PM Extracts Injection

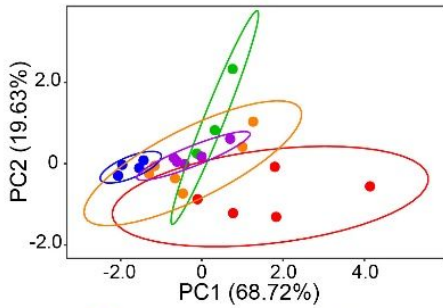

- Control - San Francisco $=$ Zurich $=$ Johannesburg $=$ Beijing

(C)

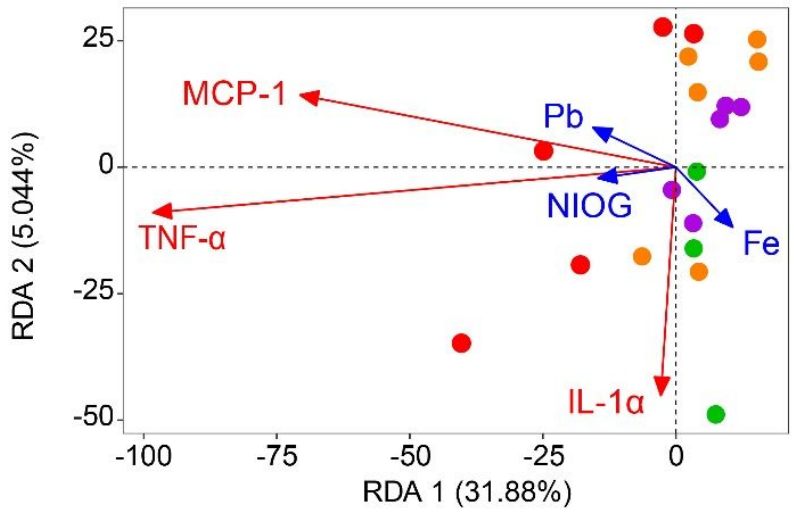

(B)

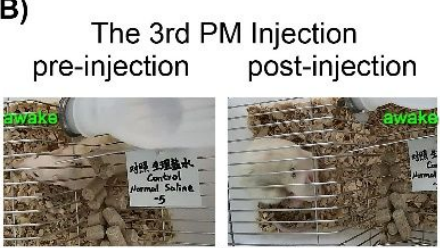

Normal saline Group

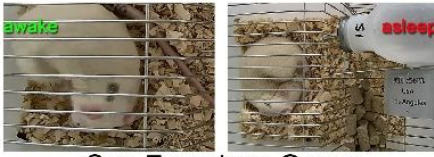

San Francisco Group

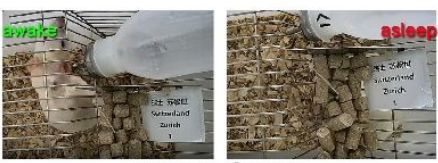

Zurich Group

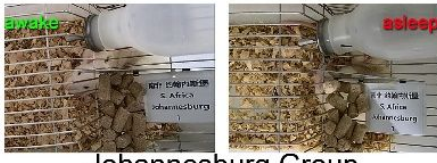

Johannesburg Group

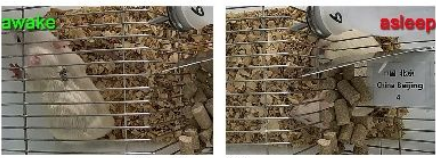

Beijing Group

239 Figure 1. (A) Concentration percentage changes and PCA analysis of serum TNF- $\alpha$,

240 MCP-1 and IL-1 $\alpha$ of rats from different groups (five groups: Normal saline, San

241 Francisco, Zurich, Johannesburg, and Beijing, each group originally (day 0) consisted

242 six rats) on three times' injections (day 0, 3 and 7). Data points represent the average

243 results from at least 3 rats after eliminating rats with outliers by Grubbs test and

244 sampling failures (Table S2 in Supporting Information), and error bars stand for the 
245 standard deviations from at least three independent measurements. The first 246 injection with $1 \mathrm{~mL}$ of $1 \mathrm{mg} / \mathrm{mL}$ extracts, second and third injections with $1 \mathrm{~mL}$ of $2472 \mathrm{mg} / \mathrm{mL}$ extracts each time. The PCA ordinations of biomarker expression profiles 248 were based on the biomarker results on the $3^{\text {rd }}$ time injection (each group had at least 2493 rats, a total of 22 rats as listed in Table S2) under exposures to PMs from four 250 different cities. PC1 (68.72\%) and PC2 (19.63\%) are the first and second principal 251 components. (B) Video snapshot of rats of different groups in $1 \mathrm{~h}$ after the $3^{\text {rd }}$ injection. 252 In general, rats injected with normal saline appeared to be more active than those 253 injected with PM extracts. Videos are provided in Supporting Information Video S1. 254 (C) Redundancy (RDA) analysis results of the three biomarker expression after the $3^{\text {rd }}$ 255 injection and PM characteristics (Normalized index of oxidant generation (NIOG) and 256 metal). The PM characteristic variables were selected by backward method according 257 to the variance inflation factor. NIOG determined by the DTT assay of samples from 258 San Francisco, Zurich, Johannesburg and Beijing are 0.0220, 0.0152, 0.0187 and 0.0114, 259 respectively. ${ }^{4} \mathrm{Fe}$ and $\mathrm{Pb}$ levels were determined by ICP-MS a previous study. ${ }^{8}$ Each dot 260 in the figure represents an independent rat injection test.

For all biomarkers, the concentration percentage changes generally increased and 263 differences between five groups were shown to be increasingly substantial with the 264 sequential PM extract injection as shown in Figure 1(A). With regard to the biomarker 265 concentration percentage changes after the third injection, biomarker levels between 266 five groups were statistically different (TNF- $\alpha$, and MCP-1 were more sensitive) ( $p$ 267 values<0.05). Zurich group had the highest increase rates in IL-1 $\alpha$; while San Francisco 268 group had the highest for TNF- $\alpha$ and MCP-1. On the other hand, Johannesburg and 269 Beijing groups tended to have comparable percentage increases in their 270 corresponding serum biomarkers. PCA results revealed a clear contrast in biomarker 271 expression profiles of rats between different groups. The biomarker expression profile 272 of the San Francisco group was very different from that of the control group (normal 273 saline) and the biomarker expression profile of the Beijing group was the closest to 
274 that of the control group. In our previous work using the same PM samples, breath275 borne IL-6 was shown to be higher in exhaled breath collected from rats injected with 276 PM samples collected from Zurich and San Francisco than those from Beijing and 277 Johannesburg. ${ }^{8}$ Innate immune cells are believed to recognize PM extracts in the 278 blood to activate immune and acute phase response with the expression of 279 inflammatory mediators such as TNF- $\alpha$ to defend against foreign agents and repair 280 tissue injury. ${ }^{19}$ Different biomarkers can be also synergistic and mutually promoted. 281 For example, TNF- $\alpha$ can regulate the production of IL- 6 and MCP- $1,{ }^{20}$ while MCP-1 as 282 a chemokine in return indirectly promoted the secretion of IL-1 and IL- 6 by recruiting 283 leucocytes and leading them to inflammatory sites in the body. ${ }^{21}$ Besides, the 284 increased IL-1 $\alpha$ observed in this study might be due to acute tissue injury as the IL-1 $\alpha$ 285 was known as an injury indicator rather than a pro-inflammatory mediator in the 286 immune and defense system..$^{22}$ Therefore, these findings indicate rats from Zurich and San Francisco groups injected even with the same mass PM as other groups yet suffered a much more serious inflammatory responses, which was most likely due to more toxic PM samples collected from the corresponding cities. Exposure to PMs from different cities caused different expression of biomarkers in rats' blood. As shown in Figure $1(C)$, RDA analysis showed that TNF- $\alpha$ and MCP-1 were more sensitive to PM toxicity (NIOG) than IL-1 $\alpha$; while among the metals $\mathrm{Pb}$ and Fe were shown to be involved in the expressions of the biomarkers. In an in vitro study, it was shown that $294 \mathrm{PM}_{2.5}$ from Beijing with higher burden of metals and PAHs exhibited different toxic 295 potencies than Guangzhou at equal mass concentrations. ${ }^{23}$ In another work, it was

296 found that the oxidative potential by acellular assays of PM per unit of mass from 297 Beijing was even lower compared to that of Zurich. ${ }^{24}$ In a toxicology study based on 298 rat model, $\mathrm{PM}_{2.5}$ collected from California, USA was shown to have greater lung 299 toxicity than $\mathrm{PM}_{2.5}$ from Shanxi, China at equal mass concentration which appears to 300 be driven by more oxidized organic carbon and copper content. ${ }^{25}$ The experimental 301 data showed that rats responded differently to PMs from different cities with different biomarker expressions, which on the other hand revealed the differences in PM 
toxicity and health mechanisms.

In general, for exposure groups, there were significant increases in the average concentration percentage changes of biomarkers for the three separate injections as shown in Figure 2 (A), ( $p$-value $<0.001$, Kruskal-Wallis One Way Analysis of Variance on Ranks). In contrast, concentration percentage changes of biomarkers for the control group did not change significantly ( $p$-value $=0.260$ ). In other studies, it was also shown that repeated PM exposure caused 10 times higher levels of biomarkers than single exposure such as TNF- $\alpha$, suggesting stronger inflammatory response in rats due to repeated exposures. ${ }^{26}$ These results indicate that prior PM exposure is also an

314 from the same sources.
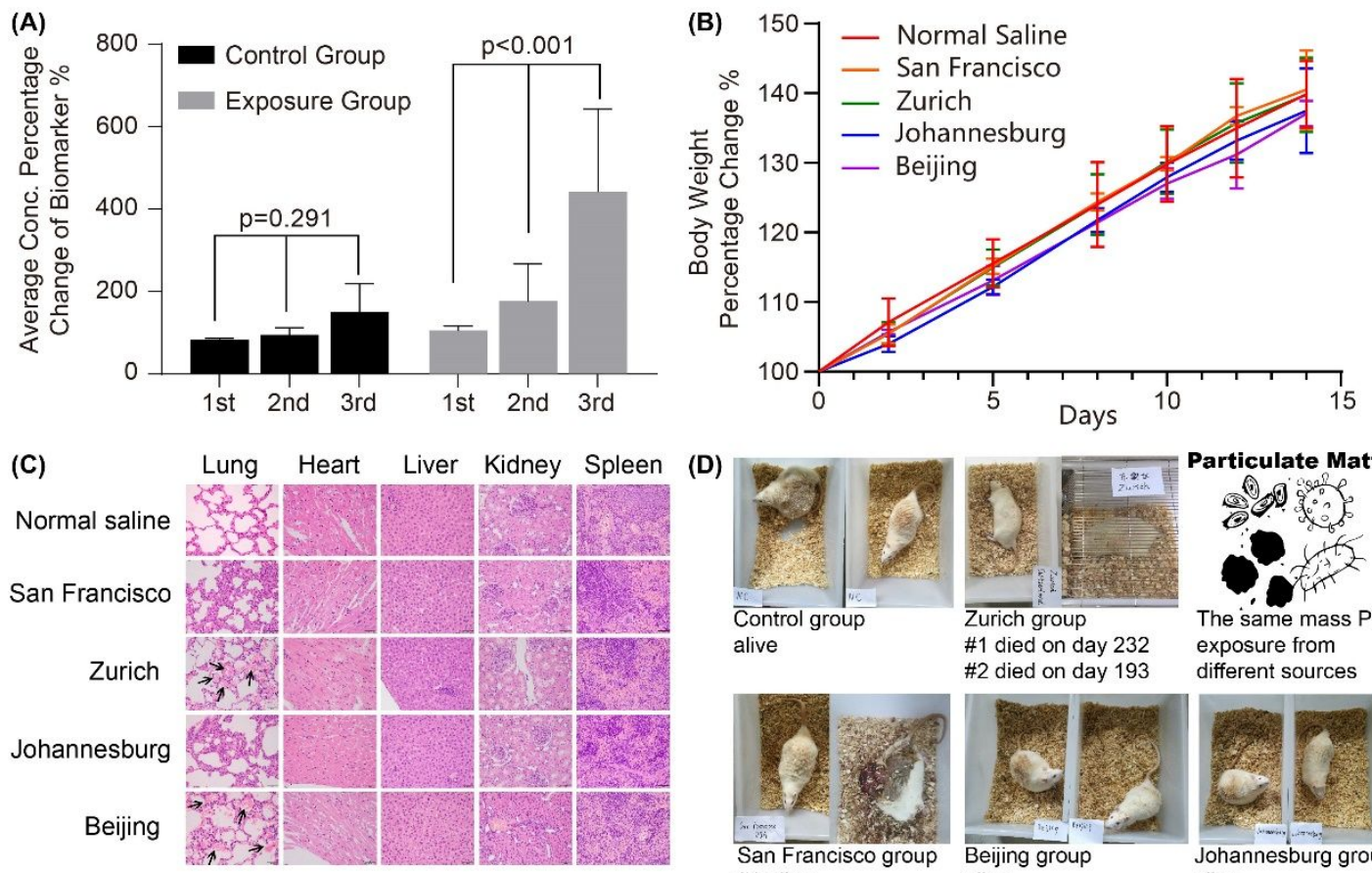

(D)
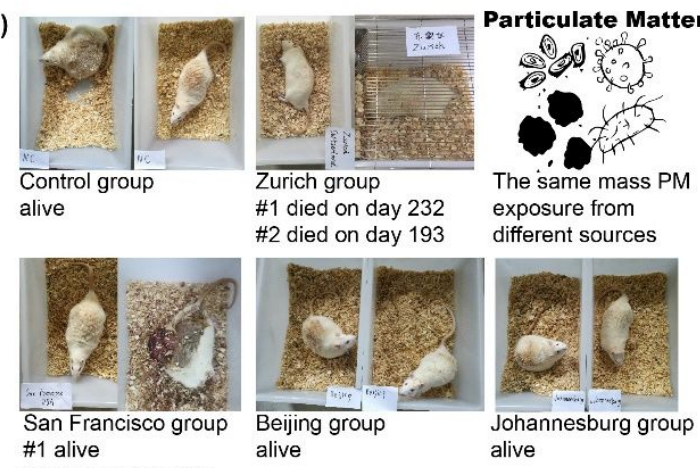
different sources

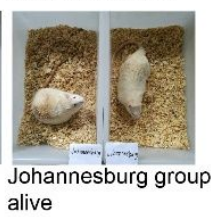

Figure 2. (A) Average biomarker concentration percentage changes of control and exposure groups for three biomarkers (TNF- $\alpha$, MCP-1 and IL-1 $\alpha$ ) at three injections.

319 The sample size ( $\mathrm{N}>=3$ ) for each group after excluding outliers using Grubbs test were shown in Table S2 (Supporting Information). (B) Average rat body weight percentage 
321 changes between different groups (five groups, each group consisted six rats) in the 322 first fourteen days. (C) The histology images of organs of rats from different groups by 323 HE stains (40X). Hemorrhage in lung alveoli was marked with black arrows in the figure. 324 (D) Photo of rats left for long-term observation until day 473 (five groups, each group 325 had two rats left for observation after the exposure experiment). Two rats from the 326 Zurich group and one rat from the San Francisco group died during the observation period. One rat from the control group and one rat from the San Francisco group developed a tumor. "*" indicates a significant difference at $95 \%$ confidence level by ttest. Data points represent the average results from at least 3 rats for Figure $2(A)$, and 6 rats for Figure 2 (B) , and error bars stand for the standard deviations.

In addition to the observation of the acute health effects in the 14 days experiments, 2 rats from each group (due to lab space limitation) were used as an additional evidence to observe how the PM injection affects the rats' health over a longer time period. Body weight of rats were recorded consequently throughout the study. As shown in Figure 2 (B), in the exposure experiment stage (three injections), the rat body weight percentage between different groups are similar as of day 14 ( $p$ value $=0.669$, one-way ANOVA analysis). In the following 459 days, as shown in Figure S2, two rats of San Francisco and Zurich groups continued to gain the most weight, followed by the control group, the Johannesburg group, and the Beijing group. In a 341 previous rat study, it was also found that breathing polluted air resulted in metabolic dysfunction and weight gain. ${ }^{27}$ In another study, hemorrhage was observed in the lung 343 alveoli of rats injected with $\mathrm{PM}_{2.5}$ extracts from samples collected on haze days. ${ }^{15} \mathrm{In}$ 344 this study, after the rats were sacrificed by anesthesia, hemorrhage was also observed 345 in lung alveoli of rats from Zurich and Beijing groups (as shown in black arrows in 346 Figure 2 (C)). While for other organs such as heart, liver, kidney and spleen, there were no obvious injuries. It's known that the lung is the organ directly suffering from PM by 348 inhalation. The results of our study suggested that the PM extracts entering blood would further spread and directly or indirectly damage the lung. The reason might be 
350 that alveoli as well as the apillary vessels have a single layer of epithelial cells, which 351 makes them more vulnerable to be attacked. Decreased blood flow velocity might 352 have also contributed to more interaction of PM extracts and alveoli tissue.

In addition, as shown in Figure 2 (D), two rats of Zurich group died naturally on 355 day 193 and 232, respectively. There are three rats from the control, San Francisco 356 and Beijing group have developed tumors (not known if they were benign and 357 malignant). Nonetheless, studies have shown that there is a significant correlation 358 between the occurrence of cancer and the exposure of PM. ${ }^{28}$ In the follow-up 359 experiments, any behavior observations after 14 days since the initial exposure did 360 not have a statistical power, but only served as additional information as mentioned 361 for the rats with PM exposure from different sources. Overall, the results from Figures 3621,2 indicate that source-specific PMs indeed caused different health effects. 363

\section{PM Toxicity is Correlated with Expression of Specific MicroRNAs}

In order to investigate the mechanism of rats' responses to PM injection exposure, 366 microRNA levels in blood samples were analyzed. Fold percentage changes of 367 concentrations of blood microRNAs of rats from different groups before and $1 \mathrm{~h}$ after 368 the third injection are shown in Figure $3(A)$. 


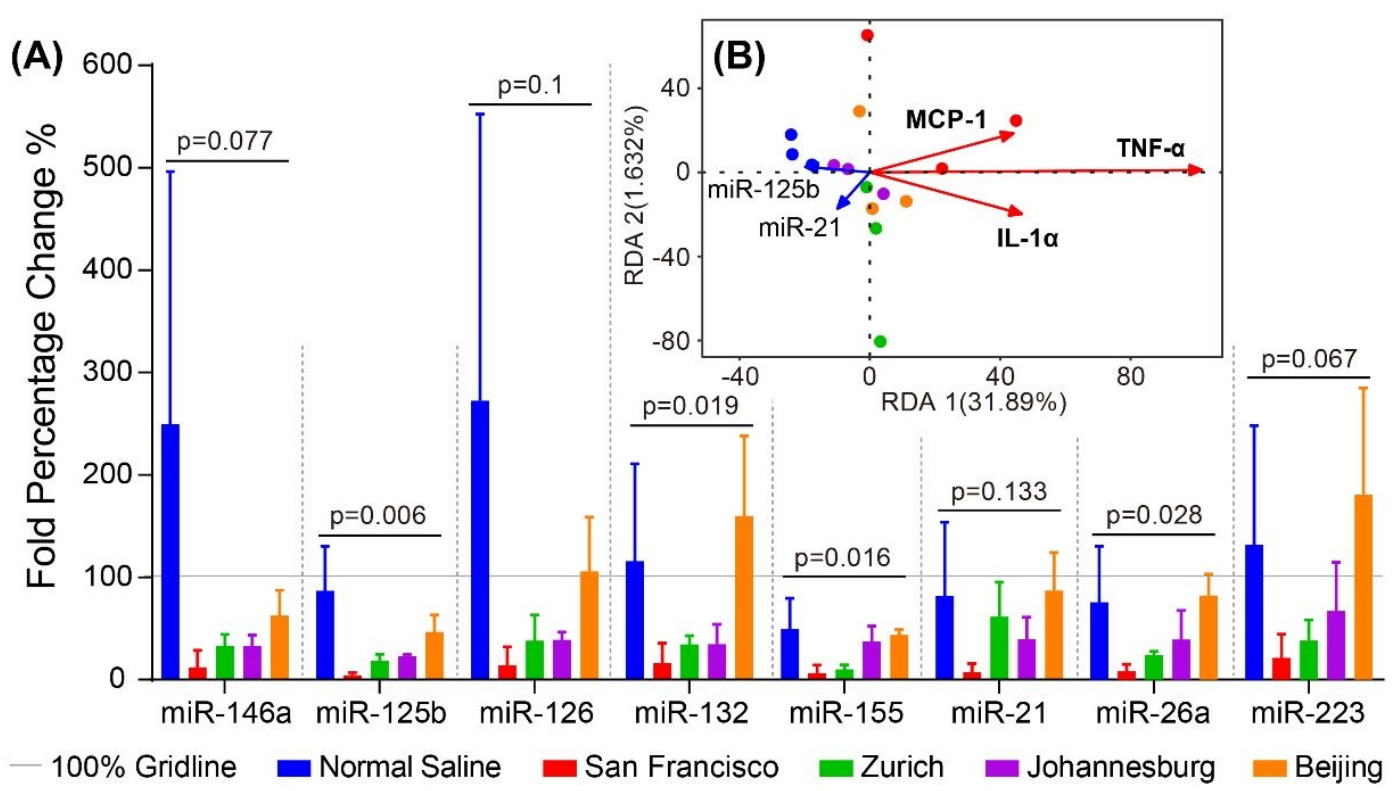

Figure 3. (A) Concentration fold percentage changes of blood microRNAs of rats from five groups before and $1 \mathrm{~h}$ after the third injection of $1 \mathrm{~mL} 2 \mathrm{mg} / \mathrm{mL}$ PM extract. Each group consisted six rats at the beginning of the third injection experiments. Data points represent averages and standard deviations of measurements from at least 3rats after eliminating rats with data outliers or rats with catheter blockage without samples. (B) Redundancy (RDA) analysis results of the biomarker expression profiles (Figure $1(A)$ ) and microRNA levels. The microRNA variables were selected by backward method according to the variance inflation factor. The miR-155 and miR-21 were shown to be negatively correlated with three biomarkers (TNF- $\alpha$, MCP-1 and IL$1 \alpha)$.

Down-regulation of the microRNAs among all the exposed groups were observed 1h after the third injection. In general, the down-regulation of microRNA expression indicated the development of immune and inflammatory reactions during the third injection exposure. Similar findings were reported, e.g., several microRNAs such as miR-21, miR-26, miR-132 and miR-126, etc., could mute immune or inflammatory responses via inhibition of targeted mediators such as protein PDCD4, P300 and VEGF. ${ }^{29-31}$ In particular, miR-146a and miR-125b are thought to inhibit the production of IL-6 and TNF- $\alpha .{ }^{32-34}$ In this study, the decline of these two microRNAs are in support 
390 of the elevated serum MCP-1 and TNF- $\alpha$ levels. Previously, it was also reported that 391 miR-125b was down-regulated while miR-155 was up-regulated in both mice and Raw 392264.7 macrophages under Lipopolysaccharide(LPS)-induced inflammation. ${ }^{34}$ In our 393 study, as shown in Figure 3 (B), the RDA (Redundancy analysis) results revealed that 394 the miR-125b and miR-21 levels were negatively correlated with the three biomarkers 395 suggesting that miR-125b and miR-21 might have played important roles in the 396 regulation of biomarker production. And miR-125b was observed to be more closely related to TNF- $\alpha$ as observed in the figure. Regarding the microRNA levels, San Francisco and Zurich groups generally had the largest downregulation rates, suggesting that PM samples from San Francisco and Zurich were more toxic than those from Beijing and Johannesburg. These results are generally consistent with the 401 biomarker results above. The oxidative potential of the same PM samples from these cities but without the filtration were measured using dithiothreitol (DTT) assay in our 403 previous study. ${ }^{4}$ Normalized index of oxidant generation (NIOG) determined by the DTT assay of samples from San Francisco, Johannesburg, Zurich and Beijing are 0.0220, 405 0.0187, 0.0152 and 0.0114 , respectively. ${ }^{4}$ The PM samples with stronger oxidative potential (NIOG), e.g., those from Zurich, are more likely to generate more ROS, thus inducing stronger oxidative damage. The dose-response type relationship between NIOG and different microRNAs levels are shown in Figure 4. Generally, all microRNA expression levels were shown to decrease with increasing PM oxidative potential 410 presented in NIOG (PM toxicity) ( $p$-values<0.05), except for the miR-155 ( $p$ 411 value $=0.1239$ ). Compared to the RDA analysis results of the microRNA regulation and biomarker expression, the miR-155 expression did not well correlate with the results obtained using the DTT assay ( $p$-value $=0.1239)$. This partially could be due to the limitation of the DTT assay in measuring overall PM toxicity. Among all studied miRNAs, miR-125b and miR-21 had the best correlations $\left(r^{2}=0.6332\right.$, and 0.5705 , respectively) 417 correlations were also statistically significant ( $p$-value $=0.0007$ and 0.0018 , 418 respectively). By searching available gene targets at http://www.microrna.org, we 
419 found miR-125b has 1,254 gene targets for Rattus norvegicus, including Wee1 and $420 \mathrm{H} 3 \mathrm{f} 3 \mathrm{~b}$ genes; while miR-155 has 5,445 gene targets for Homo sapiens, including ASF1A 421 and ARID2 (Top 20 genes are attached in Supporting Information Table S3). And 422 specific targets for each miRNA could not be simply derived using the data from this 423 work. These results indicated that different oxidative potentials of PMs could lead to 424 different down-regulations of specific miRNA expressions, thus causing different 425 toxicological effects.

426

427 


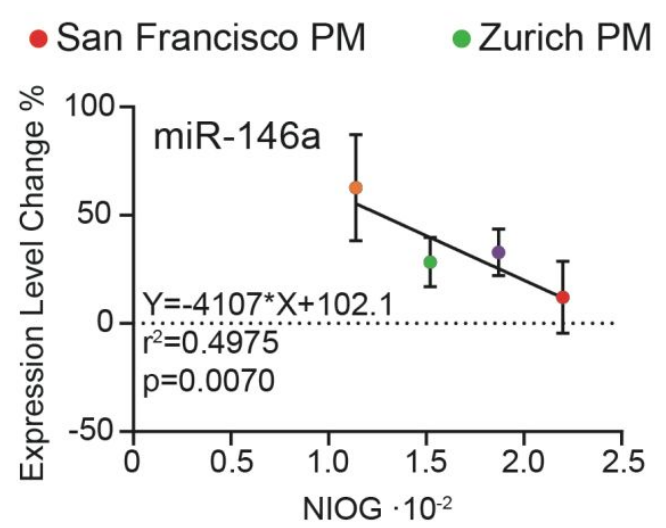

- Johannesburg PM • Beijing PM
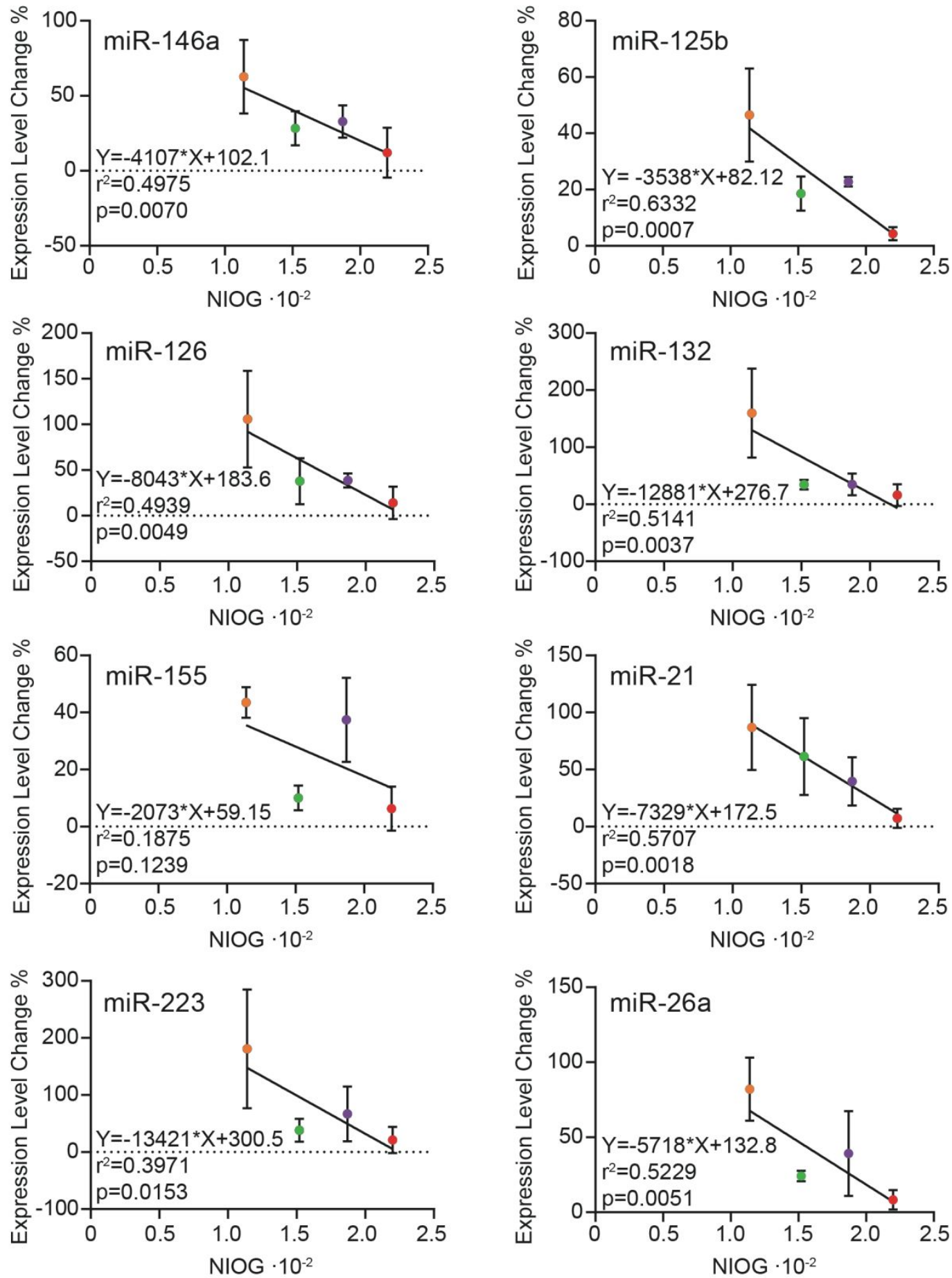

PM Oxidative Potential

429 Figure 4. Linear regressions between oxidative potentials of PM samples and different 430 microRNA expression level changes before and 1 hour after the third injection. The 431 oxidative potentials of the same PM samples were determined by DTT assay in our 432 previous study ${ }^{4}$ and presented in normalized index of oxidant generation (NIOG). Data 
points represent averages and standard deviations from at least three rats.

434

On the other hand, results from Figure 4 hint that some miRNAs can be used as a target for novel method against the pollutant exposure, such as PMs here. In the past, protein biomarkers have been already investigated in fighting against the diseases. For example, the IL-6 inhibitor, tocilizumab, has been used for the treatment of rheumatoid arthritis, juvenile idiopathic arthritis, and Castleman disease. ${ }^{19}$ Therapeutic blockade of TNF- $\alpha$ is highly beneficial in case of chronic inflammatory conditions including rheumatoid arthritis. ${ }^{35}$ An earlier study also suggested that IL-1 inhibitor can be used to treat severity of sepsis, colitis, arthritis and diabetes. ${ }^{36}$ Since the production of biomarkers are regulated by microRNAs, it would be more efficient to modulate the expression of microRNAs using corresponding inhibitors or promotors. Such efforts have been already ongoing. For instance, enforced expression of miR$125 \mathrm{~b}$ was shown to have resulted in remarkable reversal of LPS-induced increases in lung permeability as assessed by reductions in total protein, albumin and IgM in bronchoalveolar lavage fluid, indicating potential application for miR-125b-based therapy to treat clinical acute respiratory distress syndrome (ARDS). ${ }^{37}$ Another relevant study used miR-155 for suppressing expression of programmed death ligand1 (PD-L1), showing remarkable efficiency and improvement in treating solid cancers. ${ }^{38-}$ ${ }^{39}$ Here, we found that PM exposure led to down-regulations of both miR-125b and miR-21, which were apparently influenced or gated by the PM toxicity. Accordingly, in the future controlling the expression of these two microRNAs can offer a solution to protect people against ambient PMs.

\section{Health mechanisms of different sourced PMs with different toxicity}

PM is a complex and heterogeneous mixture whose composition varies greatly from one place to another. ${ }^{4}$ In a recent study, PMs from different countries were shown to have varying toxicity as determined by DTT method. ${ }^{4}$ Among PM contents, metals are generally studied due to its resistance to biodegradation, potential 
462 damages to the nerve system and genotoxicity to DNA damage. ${ }^{40-42}$ The redox 463 potential of transitive metals, such as $\mathrm{Fe}, \mathrm{Cu}, \mathrm{Zn}, \mathrm{Mn}$ etc., were thought to play an 464 important role in the oxidative and inflammatory injuries as characterized with 465 increasing biomarkers including C-reactive protein (CRP), IL-6, TNF- $\alpha, \mathrm{IL}-8,8-\mathrm{OHdG}$, 466 etc. ${ }^{43-45}$ In our previous study, the concentrations of metals in normal saline and PM extracts of the same PM samples from different cities were analyzed. ${ }^{8}$ Concentrations 468 of metals such as $\mathrm{Cu}, \mathrm{Zn}, \mathrm{Fe}, \mathrm{Cr}, \mathrm{Ni}, \mathrm{Mo}$ and $\mathrm{Mn}$ from PM extracts were significantly higher than those from normal saline. Among all the metals studied for the PMs, Fe was the most dominant species, followed by $\mathrm{Zn}$ and $\mathrm{Cu}$. Previous studies have shown that metals in $\mathrm{PM}_{2.5}$ can induce oxidative stress and cause inflammatory injury, as characterized with evaluated biomarker levels such as IL-6 and TNF- $\alpha$ in airways. ${ }^{46-50}$ 473 The PMs from Zurich (City A) and Johannesburg (City D) had relatively higher level of 474 Fe, Zn, Mo, Co; while PM from Beijing (City B) had relatively high level of $\mathrm{Mg}, \mathrm{Cu}, \mathrm{V}, \mathrm{Ni}$, and San Francisco had the highest Pb level. ${ }^{8}$ As discussed above, Figure 1 (A) shows Pb and Fe could have been more involved in down-regulations of miRNAs such as miR125b and miR-21. Different metal levels might contribute to different toxicity of PMs. However, the specific contribution of single metal and possible synergy mechanisms 480 of different metals are not clear and need to be further investigated.

In addition to metals, biological components (endotoxin, viruses, bacteria etc.) and organics such as polycyclic aromatic hydrocarbons (PAHs) of PMs are also able to induce adverse health effects to human. ${ }^{51}$ In our previous study, the bacterial species of the PM samples from these cities were measured using high-throughput gene sequencing analysis. ${ }^{8}$ Among the top 10 bacteria phyla, the proportion of Gramnegative bacteria in samples from San Francisco, Zurich, Johannesburg and Beijing are $68.19 \%, 57.15 \%, 62.59 \%$ and $54.07 \%$, respectively. ${ }^{8}$ Endotoxins released by dead and damaged Gram-negative bacteria can induce the release of acute response 489 biomarkers such as CRP and promoting the inflammatory reaction. ${ }^{52-53}$ Our previous 490 study found in the PM samples used here but without the filtration that total bacteria, 
491 culturable fungi and certain metals such as $\mathrm{Cr}$, Mo, and $\mathrm{Na}$ strongly influenced the oxidative potential of $\mathrm{PM} .{ }^{4}$ The filtration in this work would have removed those insoluble and larger particles such as bacteria and fungi, which could influence the miRNA expressions otherwise. In addition, the size distribution of PM components is another important factor for their toxicity. For example, a recent work showed that Zurich PM samples had a particle peak at the size of $\sim 40 \mathrm{~nm}$, while Beijing's PM samples did not have such a peak. ${ }^{24}$ Particles in small sizes such as $\mathrm{PM}_{2.5}$ and nanoparticles (NPs) are thought to be more harmful to humans due to its ability to enter the deep respiratory system, and even permeate into blood circulation through gas-blood barrier and possibly translocate to the brain. ${ }^{54-58}$ Further studies about the contribution of different components of various sizes including those soluble organics to the PM toxicity are warranted.

Adverse health effects of PMs have been widely investigated during the past 505 decades. ${ }^{59}$ It is well known that inflammation and oxidative stress play pivotal roles in PM-induced health effect. ${ }^{60-62}$ Here, we employed a PM-toxicity protocol based on rat intravenous injection to investigate different toxicities of PMs from different cities, and also its dose-response relationship with microRNA regulations. Our study revealed that PM water-soluble extracts could induce both acute and chronic adverse health effects when injected into blood circulation. Repeated exposure can make immune response more sensitive as characterized by higher increase rate of inflammation biomarkers. Recognized in playing important roles in the immune and inflammatory 513 process ${ }^{9,12}$, down-regulation of microRNAs triggered a "brake release" effect, causing 514 increases in levels of biomarkers such as MCP-1 and TNF- $\alpha$ as observed in our study. However, it should be noted that the signal pathways by which expressions of specific 516 miRNAs influence the biomarker levels such as MCP-1 and TNF- $\alpha$ needs to be further 517 explored. Using the same protocol, previously we have shown that different mass 518 levels of the same source PMs resulted in different levels of health effects. ${ }^{15}$ Here, we 519 further demonstrated that the same mass PMs yet from different sources were shown 
520 to have exhibited clearly different toxicities. These results in general agree with those 521 results obtained using a DTT assay for these cities. Influenced by chemicals, biologicals 522 and their size distributions, differences in PM toxicities among the studied cities 523 suggest that current environmental air quality standards of PMs should be revised 524 according to its local PM toxicity, and current PM mass level policy only tells one side 525 of the whole story. Our data for the first time showed that there exists a doseresponse type relationship between PM toxicity and microRNA regulation, and 527 different sourced PMs selectively influence the expressions of specific miRNAs. The 528 findings from our study imply that controlling the expressions of certain microRNAs 529 such as miR-125b and miR-21 through novel inhibitors can possibly offer a solution to 530 protect people from the adverse health effects of ambient PMs. Such a potential 531 application from this work warrants future investigations. While a lot of 532 epidemiological studies investigated the health effects of PM exposure, here we 533 developed an animal based protocol, i.e., injecting the PM extract directly into the 534 blood circulation, for studying the toxicity of PMs, and used it to analyze the 535 differences in toxicities of PMs collected from four different cities with different air 536 pollution conditions. However, the results from this work do not represent the true 537 exposure of PM and can be only interpreted as the comparison of toxicity differences 538 of PMs from different cities through the same exposure procedure. Nonetheless, the 539 results to some extent can serve as a reference for discussing the true exposure in 540 addition to providing a comparison. The results from this work would provide a 541 valuable reference for considering the PM toxicity difference when dealing with PM 542 associated air quality for many different cities.

\section{Acknowledgements}

545 This study was supported by the NSFC Distinguished Young Scholars Fund 546 Awarded to M. Yao (21725701), and Ministry of Science and Technology (grants 547 2016YFC0207102, 2015CB553401). 


\section{Ethics Approval and Consent to Participate}

All animal experiments in this study were approved by the Laboratory Animal

551 Ethics Committee of Peking University (Granted Number: LA2017204), and were

552 performed in accordance with the Guideline for Animal Experiments of Peking

553 University.

554

555

\section{Competing Interests}

556

The authors declare that they have no competing interests.

557

\section{Supporting Information}

The microRNA extraction and qRT-PCR detection procedure, including the cycling

560 conditions and primers;

561 Scheme of the exposure experiment procedure;

Body weight percentage change of single rat after the exposure experiment;

563 Surveillance video of the rats before and after the injection of PM extracts from 564 different cities;

565 The sample size of biomarker analysis in each group on each time injections;

566 The top 20 potential mRNAs targeted by miR-125b and miR-155 and their genes' 567 information. 
569

\section{References}

1. Cohen, A. J.; Brauer, M.; Burnett, R.; Anderson, H. R.; Frostad, J.; Estep, K.; Balakrishnan, K.; Brunekreef, B.; Dandona, L.; Dandona, R.; Feigin, V.; Freedman, G.; Hubbell, B.; Jobling, A.; Kan, H.; Knibbs, L.; Liu, Y.; Martin, R.; Morawska, L.; Pope, C. A., 3rd; Shin, H.; Straif, K.; Shaddick, G.; Thomas, M.; van Dingenen, R.; van Donkelaar, A.; Vos, T.; Murray, C. J. L.; Forouzanfar, M. H. Estimates and 25year trends of the global burden of disease attributable to ambient air pollution: an analysis of data from the Global Burden of Diseases Study 2015. Lancet 2017, $389,1907-1918$.

2. GBD 2015 Risk Factors Collaborators. Global, regional, and national comparative risk assessment of 79 behavioural, environmental and occupational, and metabolic risks or clusters of risks, 1990-2015: a systematic analysis for the Global Burden of Disease Study 2015. Lancet 2016, 388, 1659-1724.

3. Chen, R.; Yin, P.; Meng, X.; Liu, C.; Wang, L.; Xu, X.; Ross, J. A.; Tse, L. A.; Zhao, Z.; Kan, H.; Zhou, M. Fine particulate air pollution and daily mortality. a nationwide analysis in 272 chinese cities. Am. J. Respir. Crit. Care Med. 2017, 196, 73-81.

4. Li, J.; Chen, H.; Li, X.; Wang, M.; Zhang, X.; Cao, J.; Shen, F.; Wu, Y.; Xu, S.; Fan, H.; Da, G.; Huang R.; Wang, J.; Chan, C. K.; Jesus, A. L. D.; Morawska, L.; Yao, M. Differing toxicity of ambient particulate matter (PM) in global cities. Atmos. Environ. 2019, 212, 305-315.

5. Suhaimi, N. F.; Jalaludin, J., Biomarker as a research tool in linking exposure to air particles and respiratory health. BioMed Res. Int. 2015, 962853, DOI: $10.1155 / 2015 / 962853$.

6. Zeng, F.; Wei, H.; Yeoh, E.; Zhang, Z.; Ren, Z.; Colditz, G. A.; Tworoger, S. S.; Su, X. Inflammatory markers of CRP, IL-6, TNF- $\alpha$ and soluble TNFR2 and the risk of ovarian cancer: a meta-analysis of prospective studies. Cancer Epidemiol., Biomarkers Prev. 2016, 25,1231-1239.

7. Li, R.; Kou, X.; Geng, H.; Xie, J.; Tian, J.; Cai, Z.; Dong, C. Mitochondrial damage: An important mechanism of ambient PM 2.5 exposure-induced acute heart injury in 
rats. J. Hazard. Mater. 2015, 287, 392-401.

8. Chen, H.; Li, J.; Zhang, X.; Li, X.; Yao, M.; Zheng, G. Automated in vivo nanosensing of breath-borne protein biomarkers. Nano Lett. 2018, 18, 4716-4726.

9. Vrijens, K.; Bollati, V.; Nawrot Tim, S. MicroRNAs as potential signatures of environmental exposure or effect: a systematic review. Environ. Health Perspect. 2015, 123, 399-411.

10. Sittka, A.; Schmeck, B. MicroRNAs in the Lung. In MicroRNA cancer regulation. Advances in experimental medicine and biology, DordrechtSpringer Netherlands: 2013, pp 121-34.

11. Schetter, A. J.; Heegaard, N. H.; Harris, C. C., Inflammation and cancer: interweaving microRNA, free radical, cytokine and p53 pathways. Carcinogenesis 2010, 31, 37-49.

12. Wei, J.; Li, F.; Yang, J.; Liu, X.; Cho, W. C. MicroRNAs as regulators of airborne pollution-induced lung inflammation and carcinogenesis. Arch. Toxicol. 2015, 89, 677-685.

13. Bollati, V.; Marinelli, B.; Apostoli, P.; Bonzini, M.; Nordio, F.; Hoxha, M.; Pegoraro, V.; Motta, V.; Tarantini, L.; Cantone, L.; Schwartz, J.; Bertazzi, P. A.; Baccarelli, A. Exposure to metal-rich particulate matter modifies the expression of candidate microRNAs in peripheral blood leukocytes. Environ. Health Perspect. 2010, 118, 763-768.

14. Fossati, S.; Baccarelli, A.; Zanobetti, A.; Hoxha, M.; Vokonas, P. S.; Wright, R. O.; Schwartz, J. Ambient particulate air pollution and MicroRNAs in elderly men. Epidemiology 2014, 25, 68-78.

15. Zhang, X.; Kang, J.; Chen, H.; Yao, M.; Wang, J. PM2. 5 meets blood: in vivo damages and immune defense. Aerosol Air Qual. Res. 2018, 18, 456-470.

16. Li, J.; Li, M.; Shen, F.; Zou, Z.; Yao, M.; Wu, C. Characterization of biological aerosol exposure risks from automobile air conditioning system. Environ. Sci. Technol. 2013, 47, 10660-10666. 
reverse transcription-PCR data: a model-based variance estimation approach to identify genes suited for normalization, applied to bladder and colon cancer data sets. Cancer Res. 2004, 64, 5245-5250.

18. Hofer, T.; Duale, N.; Muusse, M.; Eide, D. M.; Dahl, H.; Boix, F.; Andersen, J. M.; Olsen, O. K.; Myhre, O. Restoration of cognitive performance in mice carrying a deficient allele of 8-oxoguanine DNA glycosylase by X-ray irradiation. Neurotoxic. Res. 2018, 33, 824-836.

19. Tanaka, T.; Narazaki, M.; Kishimoto, T. Interleukin (IL-6) immunotherapy. Cold Spring Harb. Perspect. Biol. 2018, 10, a028456, DOI: 10.1101/cshperspect.a028456.

20. Zhang, H.; Park, Y.; Wu, J.; Chen, X.; Lee, S.; Yang, J.; Dellsperger, K. C.; Zhang, C. Role of TNF- $\alpha$ in vascular dysfunction. Clin. Sci. 2009, 116, 219-230.

21. Deshmane, S. L.; Sergey, K.; Shohreh, A.; Sawaya, B. E. Monocyte chemoattractant protein-1 (MCP-1): an overview. J. Interferon Cytokine Res. 2009, 29, 313-326.

22. Wang, H.; Song, L.; Ju, W.; Wang, X.; Dong, L.; Zhang, Y.; Ya, P.; Yang C.; Li, F. The acute airway inflammation induced by PM2. 5 exposure and the treatment of essential oils in Balb/c mice. Sci. Rep. 2017, 7, 44256, DOI: 10.1038/srep44256.

23. Jin, L.; Xie, J.; Wong, C. K. C.; Chan, S. K.; Abbaszade, G.; Schnelle-Kreis, J.; Zimmermann R.; Li, J.; Zhang, G.; Fu, P.; Li, X. Contributions of city-specific fine particulate matter (PM2.5) to differential in vitro oxidative stress and toxicity implications between Beijing and Guangzhou of China. Environ. Sci. Technol. 2019, $53,2881-2891$.

24. Yue, Y.; Chen, H.; Setyan, A.; Elser, M.; Dietrich, M.; Li, J.; Zhang, T.; Zhang, X.; Zheng, Y.; Wang, J.; Yao, M. Size-resolved endotoxin and oxidative potential of ambient particles in Beijing and Zürich. Environ. Sci. Technol. 2018, 52, 6816-6824.

25. Sun, X.; Wei, H.; Young, D. E.; Bein, K. J.; Smiley-Jewell, S. M.; Zhang, Q.; Fulgar, C. C. B.; Castañeda, A. R.; Pham, A. K.; Li, W.; Pinkerton, K. E. Differential pulmonary effects of wintertime California and China particulate matter in healthy young mice. Toxicol. Lett. 2017, 278, 1-8. 
26. Pardo, M.; Porat, Z.; Rudich, A.; Schauer, J. J.; Rudich, Y. Repeated exposures to roadside particulate matter extracts suppresses pulmonary defense mechanisms, resulting in lipid and protein oxidative damage. Environ. Pollut. 2016, 210, 227237.

27. Wei, Y.; Zhang, J. J.; Li, Z.; Gow, A.; Chung, K. F.; Hu, M.; Sun, Z.; Zeng, L.; Zhu, T.; Jia, G.; Li, X.; Duarte, M.; Tang, X. Chronic exposure to air pollution particles increases the risk of obesity and metabolic syndrome: findings from a natural experiment in Beijing. FASEB J. 2016, 30, 2115-2122.

28. Cui, P.; Huang, Y.; Han, J.; Song, F.; Chen, K. Ambient particulate matter and lung cancer incidence and mortality: a meta-analysis of prospective studies. Eur. J. Public Health 2014, 25, 324-329.

29. O'Connell, R. M.; Rao, D. S.; Baltimore, D. MicroRNA regulation of inflammatory responses. Annu. Rev. Immunol. 2012, 30, 295-312.

30. Lagos, D.; Pollara, G.; Henderson, S.; Gratrix, F.; Fabani, M.; Milne, R. S. B.; Gotch, F.; Boshoff, C. MiR-132 regulates antiviral innate immunity through suppression of the p300 transcriptional co-activator. Nat. Cell Biol. 2010, 12, 513-519.

31. Fish, J. E.; Santoro, M. M.; Morton, S. U.; Yu, S.; Yeh, R.; Wythe, J. D.; Ivey, K. N.; Bruneau, B. G.; Stainier, D. Y. R.; Srivastava, D. MiR-126 regulates angiogenic signaling and vascular integrity. Dev. Cell 2008, 15, 272-284.

32. Zhao, J. L.; Rao, D. S.; Boldin, M. P.; Taganov, K. D.; O'Connell, R. M.; Baltimore, D. NF-KB dysregulation in microRNA-146a-deficient mice drives the development of myeloid malignancies. Proc. Natl. Acad. Sci. 2011, 108, 9184-9189.

33. Boldin, M. P.; Taganov, K. D.; Rao, D. S.; Yang, L.; Zhao, J. L.; Kalwani, M.; GarciaFlores, Y.; Luong, M.; Devrekanli, A.; Xu, J.; Sun, G.; Tay, J.; Linsley, P. S.; Baltimore, D. miR-146a is a significant brake on autoimmunity, myeloproliferation, and cancer in mice. J. Exp. Med. 2011, 208, 1189-1201.

34. Tili, E.; Michaille, J.-J.; Cimino, A.; Costinean, S.; Dumitru, C. D.; Adair, B.; Fabbri, M.; Alder, H.; Liu, C. G.; Calin, G. A.; Croce, C. M. Modulation of miR-155 and miR125b levels following lipopolysaccharide/TNF- $\alpha$ stimulation and their possible 
685 686

roles in regulating the response to endotoxin shock. J. Immunol. 2007, 179, 50825089.

35. Popa, C.; Netea, M. G.; Van Riel, P. L. C. M.; van der Meer, J. W. M.; Stalenhoef, A. F. H. The role of TNF- $\alpha$ in chronic inflammatory conditions, intermediary metabolism, and cardiovascular risk. J. Lipid Res. 2007, 48, 751-762.

36. Dinarello, C. A.; Thompson, R. C. Blocking IL-1: interleukin 1 receptor antagonist in vivo and in vitro. Immunol. Today 1991, 12, 404-410.

37. Guo, Z.; Gu, Y.; Wang, C.; Zhang, J.; Shan, S.; Gu, X.; Wang, K.; Han, Y.; Ren, T. Enforced expression of miR-125b attenuates LPS-induced acute lung injury. Immunol. Lett. 2014, 162, 18-26.

38. Yee, D.; Shah, K. M.; Coles, M. C.; Sharp, T. V.; Lagos, D. MicroRNA-155 induction via TNF- $\alpha$ and IFN- $\gamma$ suppresses expression of programmed death ligand-1 (PD-L1) in human primary cells. J. Biol. Chem. 2017, 292, 20683-20693.

39. Herbst, R. S.; Soria, J.-C.; Kowanetz, M.; Fine, G. D.; Hamid, O.; Gordon, M. S.; Sosman, J. A.; McDermott, D. F.; Powderly, J. D.; Gettinger, S. N.; Kohrt, H. E. K.; Horn, L.; Lawrence, D. P.; Rost, S.; Leabman, M.; Xiao, Y.; Mokatrin, A.; Koeppen, H.; Hegde, P. S.; Mellman, I.; Chen, D. S.; Hodi, F. S. Predictive correlates of response to the anti-PD-L1 antibody MPDL3280A in cancer patients. Nature 2014, $515,563-567$.

40. de Kok, T. M.; Hogervorst, J. G.; Briedé, J. J.; van Herwijnen, M. H.; Maas, L. M.; Moonen, E. J.; Driece, H. A.; Kleinjans, J. C. Genotoxicity and physicochemical characteristics of traffic-related ambient particulate matter. Environ. Mol. Mutagen. 2010, 46, 71-80.

41. Li, Q.; Liu, H.; Alattar, M.; Jiang, S.; Han, J.; Ma, Y.; Jiang, C. The preferential accumulation of heavy metals in different tissues following frequent respiratory exposure to PM2.5 in rats. Sci Rep 2015, 5, 16936, DOI: 10.1038/srep16936.

42. Ying, Z.; Xu, X.; Bai, Y.; Zhong, J.; Chen, M.; Liang, Y.; Zhao, J.; Liu, D.; Morishita, M.; Sun, Q.; Spino, C.; Brook, R. D.; Harkema, J. R.; Rajagopalan, S. Long-term exposure to concentrated ambient PM2.5 increases mouse blood pressure 
through abnormal activation of the sympathetic nervous system: a role for hypothalamic inflammation. Environ. Health Perspect. 2014, 122, 79-86.

43. Ramanathan, G.; Yin, F.; Speck, M.; Tseng, C.; Brook, J. R.; Silverman, F.; Urch, B.; Brook, R. B.; Araujo, J. A. Effects of urban fine particulate matter and ozone on HDL functionality. Part. Fibre Toxicol. 2016, 13, 26, DOI: 0.1186/s12989-016-01393.

44. Rhoden, C. R.; Lawrence, J.; Godleski, J. J.; González-Flecha, B. N-acetylcysteine prevents lung inflammation after short-term inhalation exposure to concentrated ambient particles. Toxicol. Sci. 2004, 79, 296-303.

45. Ghio, A. J. Biological effects of Utah Valley ambient air particles in humans: A review. J. Aerosol Med.-Depos. Clear. Eff. Lung 2004, 17, 157-164.

46. Pardo, M.; Shafer, M. M.; Rudich, A.; Schauer, J. J.; Rudich, Y. Single exposure to near roadway particulate matter leads to confined inflammatory and defense responses: possible role of metals. Environ. Sci. Technol. 2015, 49, 8777-8785.

47. Chen, L. C.; Lippmann, M. Effects of metals within ambient air particulate matter (pm) on human health. Inhal. Toxicol. 2009, 21, 1-31.

48. Carter, J. D.; Ghio, A. J.; Samet, J. M.; Devlin, R. B. Cytokine production by human airway epithelial cells after exposure to an air pollution particle is metaldependent. Toxicol. Appl. Pharmacol. 1997, 146, 180-188.

49. Thompson, A. M. S.; Zanobetti, A.; Silverman, F.; Schwartz, J.; Coull, B.; Urch, B.; Speck, M.; Brook, J. R.; Manno, M.; Gold, D. R. Baseline repeated measures from controlled human exposure studies: Associations between ambient air pollution exposure and the systemic inflammatory biomarkers IL-6 and fibrinogen. Environ. Health Perspect. 2010, 118, 120-124.

50. Schaumann, F.; Borm, P. J. A.; Herbrich, A.; Knoch, J.; Pitz, M.; Schins, R. P.; Luettig, B.; Hohlfeld, J. M.; Heinrich, J.; Krug, N. Metal-rich ambient particles (particulate matter2.5) cause airway inflammation in healthy subjects. Am. J. Respir. Crit. Care Med. 2004, 170, 898-903.

51. Cassee, F. R.; Héroux, M.-E.; Gerlofs-Nijland, M. E.; Kelly, F. J. Particulate matter 
beyond mass: recent health evidence on the role of fractions, chemical constituents and sources of emission. Inhal. Toxicol. 2013, 25, 802-812.

52. Long, C. M.; Suh, H. H.; Kobzik, L.; Catalano, P. J.; Ning, Y. Y.; Koutrakis, P. A pilot investigation of the relative toxicity of indoor and outdoor fine particles: In vitro effects of endotoxin and other particulate properties. Environ. Health Perspect. 2001, 109, 1019-1026.

53. Zhang, Y.; Gaekwad, J.; Wolfert, M. A.; Boons, G.-J. Modulation of innate immune responses with synthetic lipid a derivatives. J. Am. Chem. Soc. 2007, 129, 52005216.

54. Blank, F.; Von Garnier, C.; Gehr, P.; Rothen-Ruthishauser, B. Translocation across the air-blood tissue barrier. In Nanoparticles in the Lung, CRC Press: 2014, pp 186199.

55. Maher, B. A.; Ahmed, I. A. M.; Karloukovski, V.; MacLaren, D. A.; Foulds, P. G.; Allsop, D.; Mann, D. M.; Torres-Jardón, R.; Calderon-Garciduenas, L. Magnetite pollution nanoparticles in the human brain. Proc. Natl. Acad. Sci. 2016, 113, 10797-10801.

56. Oberdörster, G.; Sharp, Z.; Atudorei, V.; ; Elder, A.; Gelein, G.; Kreyling, W.; Cox, C. Translocation of inhaled ultrafine particles to the brain. Inhal. Toxicol. 2004, 16, 437-445.

57. Nemmar, A.; Hoet, P. H. M.; Vanquickenborne, B.; Dinsdale, D.; Thomeer, M.; Hoylaerts, M. F.; Vanbilloen, H.; Mortelmans, L.; Nemery, B. Passage of inhaled particles into the blood circulation in humans. Circulation 2002, 105, 411-414.

58. Miller, M. R.; Raftis, J. B.; Langrish, J. P.; McLean, S. G.; Samutrtai, P.; Connell, S. P.; Wilson, S.; Vesey, A. T.; Fokkens, P. H. B.; Boere, A. J. F.; Krystek, P.; Campbell, C. J.; Hadoke, P. W. F.; Donaldson, K.; Cassee, F. R.; Newby, D. E.; Duffin, R.; Mills, N. L. Inhaled nanoparticles accumulate at sites of vascular disease. ACS Nano 2017, $11,4542-4552$.

59. Rückerl, R.; Schneider, A.; Breitner, S.; Cyrys, J.; Peters, A. Health effects of particulate air pollution: a review of epidemiological evidence. Inhal. Toxicol. 2011, 

$23,555-592$.

773

774

775

776

777

778

779

780

781

782

783

60. Møller, P.; Danielsen, P. H.; Karottki, D. G.; Jantzen, K.; Roursgaard, M.; Klingberg, H.; Jensen, D. M.; Christophersen, D. V.; Hemmingsen, J. G.; Cao, Y.; Loft, S. Oxidative stress and inflammation generated DNA damage by exposure to air pollution particles. Mutat. Res., Rev. Mutat. Res. 2014, 762, 133-166.

61. Brook, R. D.; Rajagopalan, S.; Pope, C. A.; Brook, J. R.; Bhatnagar, A.; Diez-Roux, A. V.; Holguin, F.; Hong, Y.; Luepker, R. V.; Mittleman, M. A.; Peters, A.; Siscovick, D.; SmithJr, S. C.; Whitsel, L.; Kaufman, J. D. Particulate matter air pollution and cardiovascular disease. Circulation 2010, 121, 2331-2378.

62. Xing, Y.-F.; Xu, Y.-H.; Shi, M.-H.; Lian, Y.-X. The impact of PM2.5 on the human respiratory system. J. Thorac. Dis. 2016, 8, E69-E74. 